\title{
A INSERÇÃO DO CAPITAL TRANSNACIONAL E A EXPROPRIAÇÃO DE RECURSOS NATURAIS LOCAIS: UMA ANÁLISE DO AGRONEGÓCIO NO SUDOESTE PIAUIENSE
}

\author{
Elayne de Silva Figueredo ${ }^{1}$ \\ Giovana Mira de Espindola ${ }^{2}$ \\ Antonio Joaquim da Silva ${ }^{3}$ \\ Márcia Leila de Castro Pereira ${ }^{4}$
}

Resumo: $O$ atual movimento de aquisição de terras pelo capital transnacional em países ditos em desenvolvimento vem ganhando a atenção da comunidade científica, especialmente após a crise econômica mundial de 2007/2008. Neste contexto, a partir de revisão bibliográfica e de pesquisa documental, discute-se aqui a apropriação de terras pelo agronegócio, com exemplos axiomáticos do Brasil e, em especial, do sudoeste piauiense. Considerando o atual estágio da expansão da fronteira agrícola, caracterizada pela concentração fundiária e pelo controle de recursos naturais locais, destacamos o aparente avanço de tal movimento rumo ao semiárido, com o crescimento em número e área de estabelecimentos agropecuários próximos à área de transição dos biomas Cerrado e Caatinga.

Palavras-chave: MATOPIBA. Concentração Fundiária. Território. Cerrado. Caatinga.

\section{THE INSERTION OF THE TRANSNATIONAL CAPITAL AND THE EXPROPRIATION OF LOCAL NATURAL RESOURCES: AN ANALYSIS OF AGRIBUSINESS IN THE SOUTHWEST OF PIAUÍ}

Abstract: The current movement of land acquisition by transnational capital in socalled developing countries is a subject that is gaining the attention of the scientific community, especially after the convergence of the economic crisis of 2007/2008. In this context, from bibliographical revision and documentary survey, we discuss the land appropriation by agribusiness, taking as axiomatic examples Brazil and, in particular, the southwest of Piauí. Considering the current expansion of the agricultural frontier, characterized by land concentration and the control of local natural resources, we highlight the apparent advance of such movement towards the Brazilian semiarid region, with the increase of the number and area of agricultural establishments in zones near to the transition of the biomes Cerrado and Caatinga.

Keywords: MATOPIBA. Land Concentration. Territory. Cerrado. Caatinga.

\section{LA INSERCIÓN DEL CAPITAL TRANSNACIONAL Y LA EXPROPIACIÓN DE LOS RECURSOS NATURALES LOCALES: UN ANÁLISIS DEL AGRONEGOCIO EN EL SUDOESTE PIAUIENSE}

\footnotetext{
${ }^{1}$ Universidade Federal do Piauí, Programa de Pós-Graduação em Desenvolvimento e Meio Ambiente, Teresina, Brasil, elaynefigueredoo@gmail.com, https://orcid.org/0000-0002-1781-0304 ${ }^{2}$ Universidade Federal do Piauí, Departamento de Transportes e Programa de Pós-Graduação em Desenvolvimento e Meio Ambiente, Teresina, Brasil, giovanamira@ufpi.edu.br, https://orcid.org/00000003-2691-8496

${ }^{3}$ Instituto Federal do Piauí, Departamento de Geoprocessamento e Gestão Ambiental, Teresina, Brasil, antoniojoaquim@ifpi.edu.br, http://orcid.org/0000-0002-8756-9464

${ }^{4}$ Universidade Federal do Piauí, Departamento de Ciências Sociais e Programa de Pós-Graduação em Desenvolvimento e Meio Ambiente, Teresina, Brasil, marcialeila23@gmail.com, https://orcid.org/0000-0002-4531-5001
} 
Resumen: El movimiento actual de adquisición de tierras por el capital internacional en los llamados países en vías de desarrollo está ganando la atención de la comunidad científica, especialmente después de la crisis económica de 2007/2008. En este contexto, de revisión de la literatura y la investigación documental, trata sobre la apropiación de tierras por la agroindustria, con ejemplos axiomáticos a Brasil y, en particular, al sudoeste de Piauí. Teniendo en cuenta la actual etapa de expansión de la frontera agrícola, caracterizada por la concentración de la tierra y el control de los recursos naturales locales, destacamos el aparente avance de tal movimiento hacia el semiárido, con el crecimiento en número y área de establecimientos agrícolas a cerca de la zona de transición entre los biomas Cerrado y Caatinga.

Palabras clave: MATOPIBA. Concentración de la tierra. Territorio. Cerrado. Caatinga.

\section{Introdução}

Aquisições de largas escalas de terras (e de seus recursos naturais) - citado na literatura como land grabbing ou por alguns autores brasileiros como "estrangeirização de terras" - atualmente é um movimento em destaque na comunidade acadêmica, e em especial entre estudiosos da questão agrária, como economistas, antropólogos, sociólogos e geógrafos a partir da convergência mundial da crise econômica instituída nos anos de 2007/2008. Em suma, esse processo consiste na negociação de milhões de hectares de terras em âmbitos que variam do doméstico ao internacional, se utilizando de diversos mecanismos - desde intervenções na terra por meio da ação de jagunços e laranjas, até documentos cadastrados irregularmente que dão força jurídica a propriedade da terra permeando formas e motivações de origens variadas, que na maioria dos casos geram efeitos sociais e ambientais negativos, muitas vezes não considerados no debate político nacional sobre a questão (LEITE E LIMA, 2017).

É importante ressaltar que apesar de não se tratar de um assunto novo, as intensidades e características contemporâneas aglutinadas a ele trazem especificidades que têm mobilizado membros da sociedade civil, da academia, de operadores do mercado de capitais, e das entidades públicas a se posicionarem sobre a matéria. Portanto, é necessário compreender que a questão engloba um conjunto de dinâmicas e debates inter- e multidisciplinares que conecta ações globais a efeitos locais (SASSEN, 2016). Nesse sentido, a busca por investimentos em terras, impulsionada pela convergência de crises do início do século XXI, permitiu a grupos e atores privados e estatais com poder de investimento, a encontrarem na terra a garantia de ganhos especulativos, com a redução de 
incertezas que pairam em outras negociações no mercado de capital (RIDELL, 2013).

Seguramente, é inevitável conceber esse assunto como um fenômeno extremamente complexo e multifacetado. Desse modo, entre as diversas concepções sobre estrangeirização de terras, destacamos as opiniões de Oliveira (2016) e Peluso e Lund (2011), que entendem o movimento global de aquisição de terras como um processo que sempre existiu, não sendo algo novo, ele só seria o tradicional imperialismo ou, no máximo, um neocolonialismo.

Mas para defensores de movimentos sociais rurais, a exemplo a Rede Social de Justiça e Direitos Humanos, como também de relatórios de organizações internacionais, como o Comitê de Segurança Alimentar da Food and Agriculture Organization of the United Nations (FAO), o Banco Mundial e a Conferência das Nações Unidas para Comércio e Desenvolvimento, a estrangeirização de terras representa um processo atual concreto, que pressupõe a necessidade de construção de uma governança global para normalizar as transações comerciais, os riscos das operações financeiras e as consequências desse fenômeno para a sociedade, a agricultura e o meio ambiente.

Assim, várias são as literaturas que, ao analisarem estudos de caso sobre a aquisição de terras em larga escala por corporações transnacionais, que em grande parte são financiadas por capital internacional, constataram efeitos degradantes sobre o meio ambiente, e sobre as dinâmicas sociais e espaciais dos territórios (HALL, SCCONES E TSIKATA, 2015; PEREIRA E PAULI, 2016; VINHA E PEREIRA, 2016; HERRERA, 2016).

Nisto, os "novos titulares da terra", ao tempo que inserem novas dinâmicas de produção e ocupação do espaço, geram o deslocamento de comunidades locais, já que estas perdem o direito não só à terra, mas à manutenção cultural e o acesso aos recursos naturais essenciais à sobrevivência da comunidade, como a água, por exemplo. Contudo, como bem evidencia Sassen (2016), a maioria desses casos é marcada por uma característica peculiar, na qual o Estado negocia suas terras através de arrendamento, venda ou leasing de glebas, criando condições jurídicas que justificam o processo. Tal posição estatal baseia-se na "falsa justificativa" de necessidade de investimentos estrangeiros para modificar a estrutura produtiva e a infraestrutura doméstica, com vistas a ampliar a receita com as exportações. Essa percepção de "falsa justificativa" sustenta-se no recorrente quadro de endividamento dos Estados que buscam obter, de alguma forma, os recursos capazes para manter 
as contas públicas, o que, nesse caso, desmistifica o discurso governamental de validação do fenômeno de apropriação do controle de terras e dos recursos naturais.

Desse modo, o peso dado à aquisição de terras por atores internacionais faz parte da linha de raciocínio deste artigo, cujo objetivo consiste em refletir sobre definições acerca da apropriação e controle da terra e de seus recursos naturais (BORRAS JR, FRANCO E WANG, 2012) em um contexto de expropriação das comunidades locais, muitas vezes de forma violenta, e da expansão do estabelecimento de grandes empreendimentos agrícolas nas franjas da atual fronteira agrícola ${ }^{5}$ nacional (REDE SOCIAL DE JUSTIÇA E DIREITOS HUMANOS, 2018) tendo como recorte espacial a região sudoeste piauiense. Consideramos ainda o estabelecimento de grandes empreendimentos agrícolas internacionais na região citada, que territorializam o capital por meio de relações de poder, controle e expropriação das comunidades locais, em especial de camponeses, quilombolas, caboclos, quebradeiras de coco babaçu, vazanteiros e pequenos produtores rurais tradicionais. Esses povos, também conhecidos na região como posseiros, vivem sobremaneira nas áreas dos baixões (consistem em importantes reservatórios de água, em virtude das características topográficos, como os terrenos deprimidos ou áreas de vazantes cercadas por serras) e sobrevivem da pesca, roça e criação de animais domésticos (ALVES, 2006; LEITE, 2015; SILVA, 2016).

Historicamente, tais trabalhadores utilizavam as chapadas para a alimentação do gado, explorar o extrativismo vegetal e cultivar lavouras de sequeiro. Com a ocupação das chapadas, comandada pelo agronegócio, e devido uma parcela significativa das famílias não possuírem a posse jurídica da terra, o sudoeste piauiense tem revelado graves processos de perda e expulsão da terra, cujas famílias têm redefinido suas estratégias de sobrevivência marcadas principalmente por migrações para as zonas periféricas dos centros urbanos, pelo trabalho assalariado temporário nas agroindústrias e pelo encurralamento nos baixões (ALVES, 2006; MORAES, 2009; LEITE, 2015; SILVA, 2016).

\section{Procedimentos Metodológicos}

Com o objetivo de construir uma percepção própria para o fenômeno da apropriação de terras e da natureza na região sudoeste piauiense identificando os elementos que constituem e caracterizam o atual processo de produção do espaço,

\footnotetext{
${ }^{5} \mathrm{O}$ termo "Franjas agrícolas" inserido aqui pelos autores, referem-se às áreas que compreendem as bordas da região já consolidada pela atividade agrícola no Sudoeste Piauiense.
} 
frente a expropriação de comunidades locais, realizada muitas vezes de forma violenta, e do estabelecimento de grandes empreendimentos agrícolas na região que definimos por franjas agrícolas, localizada também no sudoeste piauiense. Esta pesquisa se embasa em uma revisão bibliográfica por meio de artigos científicos de periódicos e capítulos de livros, priorizando diferentes concepções e áreas do conhecimento sobre a questão posta, conforme apresentada no capítulo "Debate interdisciplinar sobre as definições de apropriação da terra e de seus recursos", este capítulo além de refletir as definições do tema, parte do esforço de apresentar os principais autores brasileiros e estrangeiros que tratam de land grabbing. Portanto, a diversidade de concepções utilizadas procura mostrar conceitos em disputa nos quais cada instituição e pesquisadores apresentam intencionalidades que variam de acordo com a sua formação acadêmica, perfil ideológico e atuação profissional.

Também se fundamenta em pesquisa documental, tendo o auxílio de relatórios, documentos e reportagens publicadas por instituições não governamentais, multilaterais e demais organizações como o Banco Mundial, a Rede de Justiça e Direitos Humanos, a Rede DATALUTA, a Comissão Pastoral da Terra (CPT), a FAO, a Transnacional Institute (TNI) e o Núcleo de Estudos e Pesquisas do Senado (NEPS), dispostos no capitulo "Fatores determinantes da efetivação de poder, controle e expropriação violenta da população camponesa pelo estabelecimento de grandes imobiliárias internacionais", mapeando os empreendimentos agrícolas com envolvimento de capital estrangeiro inseridos na região de estudo.

\section{Debate interdisciplinar sobre as definições de apropriação da terra e de seus recursos}

Recentemente, o crescente interesse acadêmico por produções científicas voltadas à apropriação do controle e posse da terra e de seus recursos naturais pode ser entendida a partir da ampliação midiática dada ao assunto, em virtude dos graves índices de violência no campo - onde, em 2017, de acordo com o relatório da CPT (2017), foram registrados 71 assassinatos, correspondendo um aumento de 153,6\% em relação ao ano de 2007 quando foram registrados 28 assassinatos -, bem como do processo de reestruturação produtiva dos territórios, marcado pela consolidação do agronegócio granífero e energético, expansão da fronteira agrícola, 
capitalização da terra, abertura comercial, aumento de exportáveis como a soja, e incentivos governamentais para a compra de terras.

Evidenciamos que a análise das novas dinâmicas inscritas pelo capital no espaço rural, na perspectiva da apropriação do controle e posse da terra e de seus recursos naturais, denota, em geral, a disciplinaridade dos campos de conhecimento científico. Todavia, por entendermos a profundidade e complexidade do fenômeno land grabbing, reconhecemos a importância do debate interdisciplinar, haja vista as várias terminologias empregadas, como green grabbing, "estrangeirização de terras", land rush, por exemplo.

Iniciaremos a análise a partir do trabalho de Castro e Igreja (2017) que utilizam o termo estrangeirização de terras como uma modalidade recente no panorama latino-americano, caracterizado por continuidade das formas de dominação colonial, opressão (cultural, social e jurídica) essencialmente relacionais e políticas, e por diferentes formas de poder. Os autores afirmam que a apropriação do controle da terra e de seus recursos significa, na prática, a captura do controle de grandes extensões de terra por meios de direitos de uso, gestão e propriedade, que desloca diversas categorias sociais por aspectos controversos, como o discurso de aproveitar economicamente e produtivamente as porções de terras caracterizadas como marginais, subutilizadas e/ou com vazios demográficos.

O trabalho de Deininger (2011) insere à discussão do land grabbing o termo land rush por constatar que, apesar da apropriação de terras por entidades estrangeiras partir de um processo antigo, atualmente estaria assumindo uma postura diferente daquela estabelecida durante a colonização por dominação. Por isso, o autor frisa que no contexto de ampla divulgação do fenômeno, algumas definições estariam carregadas de noções preconcebidas, como por exemplo a defesa de que o investimento estrangeiro em terras agrícolas nacionais é benéfico, por gerar empregos, infraestrutura social e promover o incremento de novas tecnologias.

A transferência do controle dos recursos naturais para instituições estrangeiras é tratada por Fairhead, Leach e Scoones (2012) como um processo de "commoditização da natureza" assentado na expressão green grabbing, cuja abordagem tem caráter econômico, apresentando base epistemológica distinta das análises de Castro e Igreja (2017) e Deininger (2011). Segundo Fairhead, Leach e Scoones (2012), o contexto de apropriação do controle da terra por instituições estrangeiras não pode ser justificado apenas pelo discurso da necessidade de 
produção de alimentos e agrocombustíveis, mas, sobretudo, pelo imperativo de que o plantio de determinados cultivos livres de carbono, reduz a pressão sob as florestas.

O quarto trabalho de autoria de Vinha e Pereira (2016), que analisam diferentes modelos de desenvolvimento territorial no âmbito dos embates entre agronegócio/latifúndio e campesinato, estabelece um diálogo não só entre a geografia agrária, mas também entre a geografia política e a geopolítica para evidenciar a apropriação da terra como mercadoria, bem como as novas redefinições territoriais sustentadas pelo agronegócio e assim inserir ao debate as novas manifestação da relação território-poder, que vão além das consolidadas pelos Estados Nacionais.

Em outro trabalho Sauer e Leite (2012) fazem uma pertinente discussão a respeito do fluxo de investimentos estrangeiros no setor agropecuário e de agrocombustíveis, em países do Sul, com participação de empresas do mercado de capital. No conjunto dos investimentos aplicados para a aquisição de terras e recursos naturais, se destacam aqueles voltados à produção de commodities como soja, arroz, milho, girassol, açúcar, eucalipto, dentre outros. Assim, de acordo com Borras Júnior, Franco e Wang (2012), essas culturas possuem ampla negociação no mercado global, por isso despertam o interesse de investimentos internacionais para o crescimento da produção, principalmente nos países em desenvolvimento.

O estudo de Fairbairn (2015), ao tempo em que se opõem ao termo estrangeirização de terras, por constatar que as distintas definições são ambíguas e por vezes até duvidosas, critica as atuais restrições para negociações de compra de terras por estrangeiros no Brasil, definidas pela Lei n5.709/71 de 2010, pois diante das redes de interconexão e interação territorial com os capitais financeiros nacional e internacional, tal lei não englobaria o contexto mundial que vivemos atualmente.

Frente as definições apresentadas, destacamos a divergência relacionada à tradução do termo land grabbing, que no Brasil ainda não encontrou consenso. Assim, compactuamos com as vertentes literárias que criticam o envolvimento desse tema na definição direta de grilagem de terras por grupos e/ou autores internacionais, pois ao comparar o contexto de grilagem aplicada no Brasil e a advinda do land grabbing, são observadas significativas diferenças das ações que resultam de cada processo, como no caso do land grabbing que tem dentre outros objetivos a apropriação dos recursos naturais da terra. Já a grilagem acreditamos restringir-se a processos de aquisição ilegal de terras, consolidadas a partir da 
falsificação de títulos de posse sobre terras devolutas ou de terceiros, bem como também sobre prédios indivisos, ocorrendo tanto em âmbito rural quanto urbano diferentemente do land grabbing atualmente mapeada somente em âmbito rural.

Diante de tais definições, reconhecemos as correntes de pensamento que criticam o uso do termo land grabbing para designar a grilagem de terras no Brasil por grupos ou atores estrangeiros, posto haver imprecisão na interseção das ações e objetivos entre as duas categorias, inclusive porque dentre as finalidades de land grabbing destaca-se a apropriação dos recursos naturais da terra, como água, os estoques de vegetação, por exemplo.

Corroboramos também com as posições intelectuais que desqualificam land grabbing como sinônimo de estrangeirização de terras, pois este termo supõe a apropriação de terras somente por entidades internacionais. Contudo, tal apropriação pode partir de empresas nacionais sob o controle de capitais estrangeiros. Por isso, nesse artigo, optamos por nos referir ao land grabbing como apropriação do controle da terra e de seus recursos naturais por agentes nacionais ou internacionais, pois inferimos que a utilização dessa percepção contribui para a contextualização e explicação do fenômeno para comunidade geral.

Assim, entendemos land grabbing como um processo de apropriação do controle da terra e de seus recursos naturais como água, florestas, minério, fauna, dentre outros, essa apropriação ocorreria por meio de compra, arrendamento, leasing, contratos de parceria, contratos de gaveta, parcerias empresariais, jointventure envolvendo empresas nacionais e internacionais, financeirização de empresas por fundos de investimentos de baixo ou alto risco, concessão de terras públicas ou devolutas para a expansão do agronegócio, dentre outras medidas que liberam e incentivam o uso da terra para expansão da cadeia agroalimentar e dos agrocombustíveis.

Fatores determinantes da efetivação de poder, controle e expropriação violenta da população camponesa pelo estabelecimento de grandes imobiliárias internacionais

Grandes imobiliárias fundiárias, conforme descreve a Rede Social de Justiça e Direitos Humanos (2018), são empresas que atuam no mercado de terras como fonte de rendimentos. Segundo Marques e Nakatani (2013), essas empresas reorientam o excedente dos seus capitais produtivos para o mercado financeiro em diferentes setores, dentre eles o agrícola. Assim, a especulação sobre a atividade da 
cadeia produtiva, tem por objetivo o lucro e a apropriação do controle da terra e de seus recursos naturais, incentivadas por fundos de investimentos e investidores internacionais (FREDERICO, 2016).

Nesse sentido, os diversificados fundos de investimentos - private equity, fundos de pensão, fundos soberanos e fundos de hedge - envolvidos nesse processo, encontram no Brasil, vantagens para efetivar as taxas de juros e a valorização da terra, com vistas a consolidar as "fazendas do agronegócio" (CASTRO; HERSHAW E SAUER, 2018). Dessa forma, o fluxo de investimentos do Brasil, como apresentado na Figura 1, demonstra uma característica singular se compararmos ao fluxo de outros países. O duplo movimento de capital financeiro em investimentos dentro e fora do país, apresentado na Figura 1, onde as linhas azuis representam a entrada de capital e as linhas laranjas, como saída de capital, evidenciam que além de sofrer o processo de inserção de capital estrangeiro sobre as negociações, em especial as que envolvem o processo de aquisição de largas escalas de terras no país, ele também investe capital público e privado para aquisição de terras e financiamento de atividades agrícolas fora de seu território, em países como Moçambique, Colômbia, Angola.

Assim, corroboramos com Silva $(2016$, p.172) de que em função das multiplicidades e dinâmicas dos eventos que atuam no espaço, decorrentes principalmente da globalização em curso, o território se encontra em constante movimento, marcado "pela territorialização do capital e pela oligopolização do uso da terra", o que possibilita criar e recriar especificidades como a acumulação da terra por espólio, formulada pela ideia de endogenização global de investimentos estrangeiros.

É ainda importante ressaltar que o processo de apropriação do controle de terras em largas escalas por capital transnacional e internacional não deve ser entendido apenas por acumulação de áreas de cultivos em largas extensões no formato de hectares, pois devido à questão energética (LUCON E GOLDEMBERG, 2019), inserida na convergência da crise de 2007/2008, quando observou-se no Brasil, por exemplo, o processo de apropriação do controle e posse da terra por instituições transnacionais, configurando-se então em extensas faixas de terras (compreendidas em larguras pré-estabelecida e comprimento indeterminado) destinadas a construção de linhas de distribuição energética. 
Figura 1: Fluxo de investimentos internacionais e transnacionais do Brasil com os demais países.

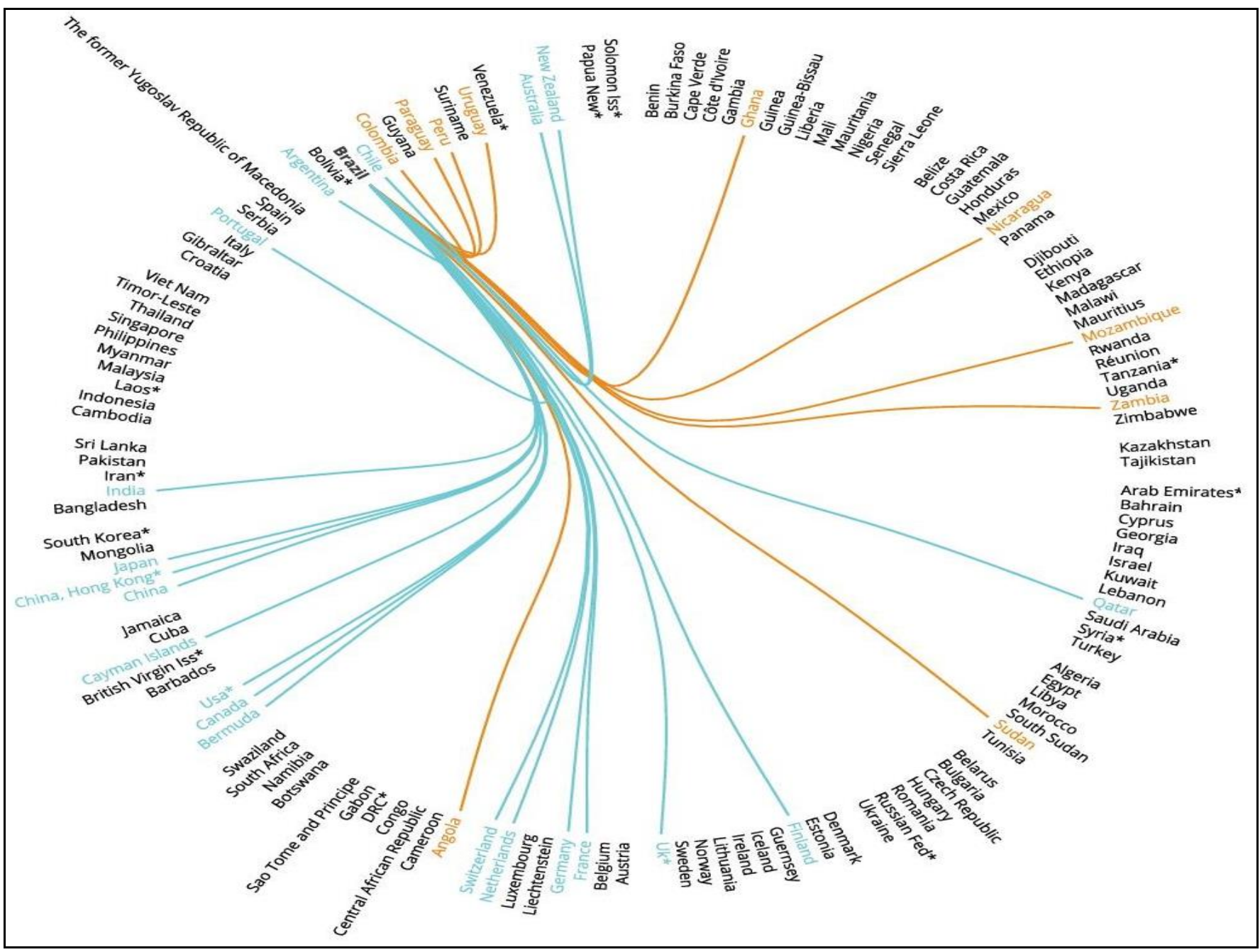

Fonte: Land Matrix (2018). Disponível: https://landmatrix.org/en/get-the-idea/webtransnational-deals/

Visto isso, passamos ao recorte espacial da região sudoeste piauiense, que apesar de ser caracterizada como zona ecótona de rica biodiversidade (com a transição dos biomas Cerrado e Caatinga) e de heterogêneos mosaicos vegetativos e diversidade de climas, solos, relevos e rios (RUFO, 2013), vem apresentando significativas mudanças na paisagem e nas sociabilidades, ocasionadas principalmente pelo avanço da expansão agrícola, face ao processo de inserção nacional e transnacional de empressas ligadas ao agronegócio (MIRANDA E SILVA, 2016).

Ressaltamos que o detalhamento dos fundos de investimentos e das empresas estrangeiras instaladas no sudoeste piauiense evidencia a natureza patrimonialista da terra e auxilia no entendimento do impacto direto causado pelas expropriações das populações camponesas e do aumento dos conflitos na região. 
Além disso, destacamos que a pressão dos investidores internacionais associada ao lobby e à interferência política da bancada ruralista no Congresso Nacional Brasileiro são fontes de poder determinantes para a expansão do mercado imobiliário de terras e do agronegócio para as áreas de abertura da fronteira agrícola particularmente o sudoeste piauiense, tem repercutido na concentração fundiária e em intensos processos de expropriação das populações camponesas, marcados pela violência.

Dados dos Censos Agropecuários de 2006 e 2017 (Quadro 1) ajudam a quantificar esses números. Na região sudoeste piauiense, foram registradas as variações de $+8,16 \%$ no número total da área em hectares compreendidas por estabelecimentos agropecuários, contra $+1,26 \%$ no número total de unidades agropecuários com esta finalidade. Em especial, destacamos alguns dos municípios que convencionamos chamar de franja agrícola do sudoeste piauiense, perante a significativa ascensão em número e hectare dos estabelecimentos agropecuários. Em Baixa Grande do Ribeiro, onde a ocupação empresarial é recente, houve aumento de 29,5\% (208 unidades) para a criação de novos estabelecimentos, com incremento de 129,7\% (262.911 hectares) em termos de áreas para um intervalo de 11 anos. Outro município que chama atenção é Brejo do Piauí que apartir do incremento de 317 (65,8\%) novos estabelecimentos agropecuários em 2017, introduziu 11.926 mil hectares de terras a atividade agropecuária do município. Já o município de Monte Alegre do Pauí, localizado próximo a municípios já consolidos no setor de produção granífera como exemplo, os municípios de Santa Filomena, Bom Jesus e Gilbués, o crescimento de 50.575 mil hectares de terras é justificado pela instalação de 517 novas unidades agopecuária. Por fim, destacamos Uruçuí, conhecido por ser pioneiro em instalar o agronegócio no Piauí e apresentar significativa infraestrutura atraindo novos investidores e o melhor PIB per capita do estado (decorrente do Valor Adicionado da Produção Agropecuária), o crescimento de 213.562 mil hectares de terras e a instalação de 18 novas unidades agropecuárias, equivalendo a uma média de 11.864 mil hectares de terra por unidade. 
Quadro 1: Evolução dos estabelecimentos agropecuários, no sudoeste piauiense, por número e área, entre os anos de 2006 e 2017

\begin{tabular}{|c|c|c|c|c|}
\hline \multirow[b]{2}{*}{ Municípios (Piauí) } & \multicolumn{2}{|c|}{$\begin{array}{c}\text { Número de } \\
\text { estabelecimentos } \\
\text { agropecuários } \\
\text { (Unidades) }\end{array}$} & \multicolumn{2}{|c|}{$\begin{array}{c}\text { Área dos } \\
\text { estabelecimentos } \\
\text { agropecuários } \\
\text { (Hectares) }\end{array}$} \\
\hline & 2006 & 2017 & 2006 & 2017 \\
\hline Alvorada do Gurguéia & 548 & 376 & 129.686 & 46.256 \\
\hline Anísio de Abreu & 1.047 & 1.306 & 18.720 & 14.049 \\
\hline Antônio Almeida & 277 & 161 & 27.557 & 35.907 \\
\hline Avelino Lopes & 1.432 & 1.256 & 69.551 & 53.932 \\
\hline Baixa Grande do Ribeiro & 705 & 913 & 202.666 & 465.577 \\
\hline Barreiras do Piauí & 280 & 245 & 14.765 & 14.947 \\
\hline Bertolínia & 408 & 413 & 34.216 & 31.284 \\
\hline Bom Jesus & 1.026 & 1.024 & 223.747 & 241.014 \\
\hline Bonfim do Piauí & 1.174 & 1.417 & 12.668 & 14.335 \\
\hline Brejo do Piauí & 482 & 799 & 16.179 & 28.105 \\
\hline Canavieira & 549 & 484 & 52.238 & 55.646 \\
\hline Canto do Buriti & 2.616 & 2.160 & 117.428 & 50.858 \\
\hline Caracol & 1.357 & 1.443 & 22.557 & 32.676 \\
\hline Colônia do Gurguéia & 233 & 302 & 15.878 & 15.271 \\
\hline Coronel José Dias & 812 & 732 & 33.179 & 50.596 \\
\hline Corrente & 1.606 & 1.469 & 125.504 & 174.809 \\
\hline Cristalândia do Piauí & 990 & 789 & 60.041 & 50.887 \\
\hline Cristino Castro & 447 & 495 & 54.494 & 63.818 \\
\hline Curimatá & 1.023 & 1.183 & 74.727 & 80.960 \\
\hline Currais & 539 & 754 & 158.151 & 190.097 \\
\hline Dirceu Arcoverde & 1.230 & 1.561 & 44.628 & 49.254 \\
\hline Dom Inocêncio & 1.962 & 1.876 & 136.820 & 171.195 \\
\hline Eliseu Martins & 459 & 493 & 26.642 & 34.119 \\
\hline Fartura do Piauí & 992 & 1.149 & 37.403 & 36.772 \\
\hline Flores do Piauí & 732 & 579 & 29.842 & 26.199 \\
\hline Floriano & 1.536 & 1.382 & 139.065 & 98.671 \\
\hline Gilbués & 1.044 & 760 & 60.584 & 111.801 \\
\hline Guadalupe & 217 & 250 & 28.171 & 27.542 \\
\hline Guaribas & 630 & 850 & 7.844 & 13.551 \\
\hline Itaueira & 1.651 & 1.476 & 61.207 & 78.112 \\
\hline Jerumenha & 247 & 191 & 66.478 & 68.938 \\
\hline Júlio Borges & 870 & 889 & 36.410 & 45.697 \\
\hline Jurema & 911 & 1.130 & 20.514 & 20.202 \\
\hline Landri Sales & 793 & 853 & 59.578 & 60.276 \\
\hline Manoel Emídio & 553 & 494 & 34.107 & 24.009 \\
\hline Marcos Parente & 352 & 421 & 24.290 & 30.117 \\
\hline Monte Alegre do Piauí & 1.091 & 1.608 & 95.013 & 145.588 \\
\hline Morro Cabeça no Tempo & 668 & 576 & 35.424 & 38.552 \\
\hline Nazaré do Piauí & 590 & 531 & 31.737 & 23.587 \\
\hline
\end{tabular}




\begin{tabular}{|c|c|c|c|c|} 
Pajeú do Piauí & 711 & 590 & 27.439 & 31.517 \\
\hline Palmeira do Piauí & 741 & 765 & 54.910 & 73.527 \\
\hline Parnaguá & 1.062 & 1.040 & 239.869 & 231.127 \\
\hline Pavussu & 668 & 647 & 24.723 & 15.173 \\
\hline Porto Alegre do Piauí & 253 & 217 & 41.593 & 20.454 \\
\hline Redenção do Gurguéia & 600 & 623 & 58.206 & 57.242 \\
\hline Riacho Frio & 627 & 429 & 64.887 & 69.315 \\
\hline Ribeiro Gonçalves & 273 & 345 & 167.292 & 215.296 \\
\hline Rio Grande do Piauí & 645 & 857 & 20.498 & 38.381 \\
\hline Santa Filomena & 481 & 640 & 142.842 & 229.098 \\
\hline Santa Luz & 443 & 435 & 37.842 & 38.685 \\
\hline São Braz do Piauí & 893 & 1.073 & 13.496 & 14.478 \\
\hline São Francisco do Piauí & 1.059 & 1.210 & 54.945 & 37.585 \\
\hline São Gonçalo do & 295 & 367 & 10.683 & 20.349 \\
\hline Gurguéia & 395 & 397 & 58.570 & 31.899 \\
\hline São José do Peixe & 3969.025 \\
\hline São Lourenço do Piauí & 1.013 & 860 & 34.405 & 24.025 \\
\hline São Miguel do Fidalgo & 270 & 207 & 23.759 & 15.921 \\
\hline São Raimundo Nonato & 3.627 & 3.664 & 66.455 & 55.193 \\
\hline Sebastião Barros & 651 & 578 & 48.246 & 58.263 \\
\hline Sebastião Leal & 446 & 502 & 102.315 & 155.251 \\
\hline Tamboril do Piauí & 510 & 592 & 15.220 & 13.248 \\
\hline Uruçuí & 1.203 & 1.221 & 327.642 & 541.204 \\
\hline Várzea Branca & 922 & 1.139 & 19.930 & 20.635 \\
\hline Sudoeste Piauiense & 51.867 & 53.188 & 4.095 .476 & 4.823 .072 \\
\hline (Total) & Fonte:1BGE & & & \\
\hline
\end{tabular}

Fonte: IBGE (2019).

Assim, a expansão da fronteira agrícola no sudoeste piauiense, além de manifestar a manutenção de práticas tradicionais no conjunto da agricultura moderna, como o arrendamento de terras principalmente para a produção de commodities, reafirma a permanência de velhas questões territoriais no Piaú, como a concentração fundiária, inclusive nas mãos de atores internacionais (BANCO DO NORDESTE, 2018; SILVA, 2016).

Por isso, na região de fronteira agrícola, como no sudoeste piauiense, relatos como os descritos pelo grupo Dataluta (2017) e a Comissão Pastoral da Terra (2017), que denunciam o empobrecimento da saúde, do trabalho e da qualidade de vida das populações camponesas decorrentes do uso de químicos nas lavouras do agronegócio e de assédios a funcionários públicos praticados por fazendeiros e especuladores interessados nas terras historicamente ocupadas pelas comunidades tradicionais, tem se tornado frequentes (BARROS, 2018). 
Ademais, para aprofundar o debate sobre a atuação das empresas e dos fundos de investimentos internacionais no sudoeste piauiense, apresentamos 0 Quadro 2, que ilustra a territorialização capitalista da terra na região entre os anos de 2013 a 2017. No entanto, reconhecemos a difícil e complexa tarefa em reunir, interpretar, caracterizar e avaliar os dados sobre o contexto de aquisição de terras por estrangeiros no Piauí, haja vista a existência de informações contraditórias ou desencontradas, documentos ou relatórios incompletos e da dificuldade em coletar dados primários sobre tais investimentos.

Quadro 2: Empresas estrangeiras atuantes no sudoeste piauiense, entre 2013 e 2017

\begin{tabular}{|c|c|c|c|c|}
\hline Razão Social & $\begin{array}{c}\text { Empresas e } \\
\text { Fundos de } \\
\text { Investimentos } \\
\end{array}$ & $\begin{array}{l}\text { Origem } \\
\text { do Capital }\end{array}$ & Uso do Solo & Municípios \\
\hline $\begin{array}{c}\text { BrasilAgro** - } \\
\text { Companhia Brasileira } \\
\text { de Propriedades } \\
\text { Agrícolas }\end{array}$ & $\begin{array}{c}\text { Cresud; JP } \\
\text { Morgan; Credit } \\
\text { Suisse } \\
\text { Heldging-Griffo; } \\
\text { Elie Horn; } \\
\text { Kopernik } \\
\text { Global Investors }\end{array}$ & $\begin{array}{l}\text { Argentina, } \\
\text { EUA, } \\
\text { Brasil }^{*}\end{array}$ & $\begin{array}{l}\text { Grãos }(e m \\
\text { rotação) } \\
\text { Mercado de } \\
\text { Terras }\end{array}$ & $\begin{array}{l}\text { Ribeiro } \\
\text { Gonçalves }\end{array}$ \\
\hline Bunge Alimentos S.A & $\begin{array}{l}\text { DuPont; The } \\
\text { Solae Company }\end{array}$ & EUA & $\begin{array}{l}\text { Cana-de- } \\
\text { açúcar, } \\
\text { Grãos (em } \\
\text { rotação) }\end{array}$ & $\begin{array}{c}\text { Baixa Grande do } \\
\text { Ribeira, Currais, } \\
\text { Uruçuí }\end{array}$ \\
\hline $\begin{array}{c}\text { Cantagalo General } \\
\text { Grains S.A. }\end{array}$ & $\begin{array}{c}\text { Companhia de } \\
\text { Tecidos Norte de } \\
\text { Minas } \\
\text { (Coteminas); } \\
\text { Grupo } \\
\text { Wembley; } \\
\text { Agrícola Estreito } \\
\text { S.A.; } \\
\text { Mitsui\&Co; GFN } \\
\text { Agrícola e } \\
\text { Participações S.A; } \\
\text { Sojitz }\end{array}$ & $\begin{array}{c}\text { Brasil*, }^{*} \text {, } \\
\text { EUA, } \\
\text { Japão, } \\
\text { Reino } \\
\text { Unido }\end{array}$ & $\begin{array}{l}\text { Grãos (em } \\
\text { rotação) }\end{array}$ & $\begin{array}{c}\text { Baixa Grande do } \\
\text { Ribeira }\end{array}$ \\
\hline CHS Inc. & $\begin{array}{c}\text { NovaAgri; } \\
\text { Multigrain; Mitsui }\end{array}$ & EUA & $\begin{array}{l}\text { Grãos (em } \\
\text { rotação) }\end{array}$ & Bom Jesus \\
\hline Enel Green Power & N. I & Itália & $\begin{array}{c}\text { Energias } \\
\text { Alternativas }\end{array}$ & $\begin{array}{l}\text { São Gonçalo do } \\
\text { Gurgueia, } \\
\text { Ribeira do Piauí }\end{array}$ \\
\hline $\begin{array}{c}\text { Insolo Agroindustrial } \\
\text { S.A. }\end{array}$ & $\begin{array}{c}\text { IPA Investimento } \\
\text { Agrícola; Harvard } \\
\text { University; Família } \\
\text { loschpe. }\end{array}$ & $\begin{array}{c}\text { Brasil }^{*}, \\
\text { EUA }\end{array}$ & $\begin{array}{l}\text { Algodão; } \\
\text { Grãos (em } \\
\text { rotação) }\end{array}$ & $\begin{array}{l}\text { Baixa Grande do } \\
\text { Ribeira, } \\
\text { Palmeira do } \\
\text { Piauí, Ribeiro } \\
\text { Gonçalves, } \\
\text { Santa Filomena, } \\
\text { Uruçuí }\end{array}$ \\
\hline Mitsui & $\begin{array}{c}\text { Multigrain; SLC } \\
\text { Agrícola }\end{array}$ & Japão & Café & $\begin{array}{l}\text { Monte Alegre do } \\
\text { Piauí, Santa }\end{array}$ \\
\hline
\end{tabular}




\begin{tabular}{|c|c|c|c|c|}
\hline & & & & Filomena \\
\hline $\begin{array}{l}\text { São João do Pirajá } \\
\text { Empreendimentos e } \\
\text { Participacões Ltda. }\end{array}$ & N. I & EUA & $\begin{array}{l}\text { Mercado de } \\
\text { terras }\end{array}$ & $\begin{array}{c}\text { Baixa Grande do } \\
\text { Ribeira }\end{array}$ \\
\hline SLC Agrícola S.A. & $\begin{array}{l}\text { SLC LandCo.; } \\
\text { Dois Vales } \\
\text { Participações; } \\
\text { Mitsui\&Co.; } \\
\text { Deustche } \\
\text { Invest I Global } \\
\text { Agribusiness; } \\
\text { Valiance Asset } \\
\text { Management; } \\
\text { Neuberger } \\
\text { Berman }\end{array}$ & $\begin{array}{c}\text { Brasil*, } \\
\text { EUA }\end{array}$ & $\begin{array}{l}\text { Algodão, } \\
\text { Grãos (em } \\
\text { rotação) }\end{array}$ & $\begin{array}{l}\text { Monte Alegre do } \\
\text { Piauí, Santa } \\
\text { Filomena }\end{array}$ \\
\hline Sollus Capital & $\begin{array}{c}\text { Los Grobo; } \\
\text { Touradji Capital } \\
\text { Management; } \\
\text { Vinci Partners }\end{array}$ & Argentina & $\begin{array}{l}\text { Mercado de } \\
\text { terras }\end{array}$ & Bom Jesus \\
\hline Sojitz do Brasil S.A & $\begin{array}{l}\text { CGG Trading; } \\
\text { Toyota }\end{array}$ & Japão & $\begin{array}{l}\text { Grãos (em } \\
\text { rotação) }\end{array}$ & $\begin{array}{c}\text { Baixa Grande do } \\
\text { Ribeira }\end{array}$ \\
\hline Tiba Agro S.A. & $\begin{array}{l}\text { Irmãos Francioni; } \\
\text { Grupo Golin; } \\
\text { Vision Brazil } \\
\text { Investments }\end{array}$ & EUA & $\begin{array}{l}\text { Mercado de } \\
\text { terras }\end{array}$ & $\begin{array}{l}\text { Monte Alegre do } \\
\text { Piauí, Santa } \\
\text { Filomena }\end{array}$ \\
\hline Terra Santa Agro & N.I. & França & $\begin{array}{l}\text { Mercado de } \\
\text { Terras }\end{array}$ & Currais \\
\hline
\end{tabular}

* Empresas declaradas brasileiras, que possuem capital estrangeiro.

** Subsidiária de empresas internacionais por meio do Join Venture.

*** Milho, soja, algodão, cana-de-açúcar dentre outras commodities.

Fonte: DATALUTA (2017), adaptado pelos autores (2019).

De acordo com o Quadro 2, os países que se destacam com fundos de investimentos diretos no sudoeste piauiense são Estados Unidos da América, Japão, Reino Unido e Itália. Supostamente, as operações de compra de terras visam a produção e expansão de commodities agrícolas. Outra evidência, revela-se à atividade específica do mercado de terras, apresentado na coluna de uso do solo, e ao estabelecimento da empresa Enel Green Power, de capital italiano, cujas estratégias de reprodução do capital orientam-se para a exploração de energias renováveis, especialmente no município de Ribeira do Piauí, onde a empresa instalará o maior parque solar da América Latina, chamado de Parque Nova Olinda. Tais situações reforçam a opinião de que nas terras situadas no sudoeste do Piauí, o capital se reproduz por meio do espectro oligopsônico das trasnacionais, onde os recursos naturais e a terra são negociados no que se poderia chamar de "compra com porteira fechada" para os grupos internacionais. 
Ainda no conjunto das empresas supracitadas no Quadro 2, destaca-se a empresa Insolo Agroindustrial S.A. em função da produção granífera, pois segundo consta no site 6 eletrônico da empresa, na safra de 2014/2015 foram ocupados mais de 67 mil hectares de terras para a produção de commodities agrícolas, e com perspectivas de expansão, pois a política de planos de negócios da empresa prevê a intensificação da área plantada, sobretudo de algodão, visando, assim, aumentar o comércio com o mercado internacional.

Vale acrescentar também, em conformidade com Pereira e Pauli (2016), que a Insolo Agroindustral S.A. foi criada em 2003 por agrônomos paranaenses que, atraídos pelos potenciais produtivos da região do Matopiba $^{7}$, onde se situa o sudoeste do Piauí, instalaram um grupo de gerenciamento de serviços e propriedades agrícolas chamado Insolo Soluções Agrícolas. Posteriormente, com o aprofundamento da crise internacional em 2008, a Insolo Soluções Agrícolas passou a receber consideráveis investimentos da lochpe-Maxion S.A., cujos imperativos administrativos e econômicos determinou o grupo a assumir definitivamente a razão social de Insolo Agroindustrial S.A. repercutindo em novas estratégicas baseadas nos interesses dos investidores, com a produção das commodities soja, milho e principalmente algodão.

Desde então, a Insolo Agroindustrial S.A. estabeleceu seis empreendimentos graníferos no sudoeste piauiense, ocupando uma área de aproximadamente 58.207 hectares, são elas: Fazendas Fortaleza e Nazaré, em Santa Filomena; Fazenda Cerro Azul, em Baixa Grande do Ribeiro; Fazenda Vista Verde, no município de Palmeira do Piauí; Fazenda Serra Grande, em Ribeiro Gonçalves e uma usina de beneficiamento de alta tecnologia e capacidade de algodão sediada no município de Uruçuí, representado na Figura 2.

\footnotetext{
${ }^{6}$ Insolo: história. Disponível: http://www.insolo.com.br/historia.html. Acesso em: 21 jan. 2019.

${ }^{7}$ Região considerada economicamente estratégica para o cultivo e escoamento da produção granífera. Matopiba é um acrônico dos estados do Maranhão, Tocantins, Piauí e Bahia e constitui uma área de franca expansão para o agronegócio devido às características naturais, como a presença de mosaicos vegetativos em florestas residuais e savanas e predominância de chapadas viáveis à mecanização.
} 
Figura 2: Distribuição espacial da Insolo Agroindustrial S.A. no sudoeste piauiense

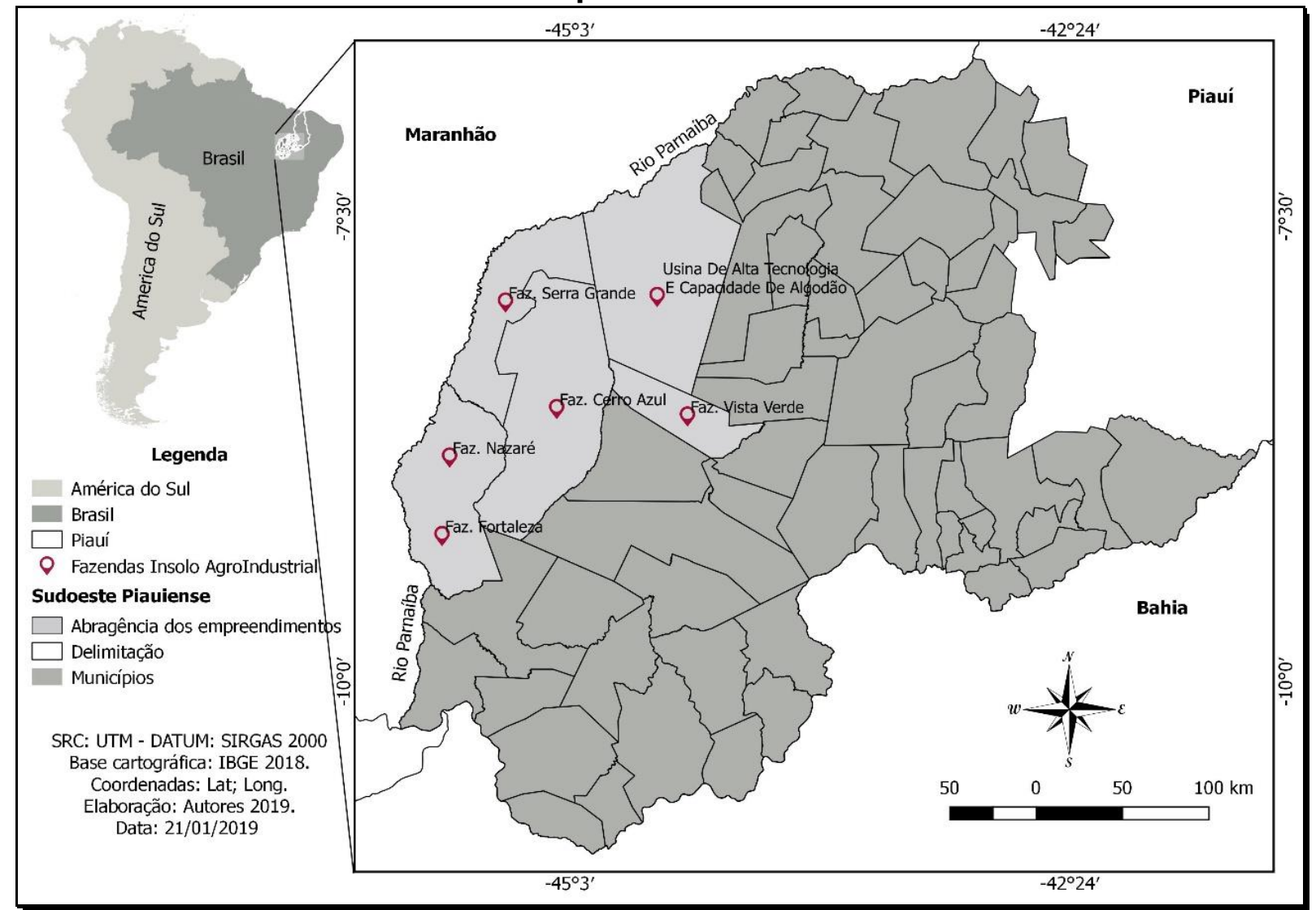

Fonte: Elaborado pelos autores (2019).

A entrada da Insolo Agroindustrial nos cerrados piauienses contou com a participação direta de capitais privado e público estadual, cujos montantes aproximados foram, respectivamente, $R \$^{8} 132.886 .301,6512^{2}$ e $R \$ 250.000,000,00$. Enfatizamos que os incentivos do governo do estado do Piauí, em 2016, foram decisivos para melhorias técnicas, principalmente na infraestrutura e escoamento da produção granífera, aumentando as vantagens competitivas da empresa.

Apesar das dificuldades de aprofundar a pesquisa sobre a referida empresa, constatamos a sua relação empresarial com a IPA Investimentos e Participações Agrícolas e com os fundos de pensão da Harvard University (Foreign pension funds and land grabbing in Brazil, 2015). A origem do montante de capital privado aplicado pela Insolo Agroindustrial S.A. para a compra e o arrendamento de terras no Piauí tinha como credor a IPA investimentos, que operava por meio de fundos de pensão de professores da Harvard University. Esse panorama configurava, além da

8 Diário Oficial. Disponível: http://www.jusbrasil.com.br/diarios/39185154/dosp-empresarial-02-082012-pg-2. Acesso em: 30 nov. 2018; Diário Oficial. https://www.jusbrasil.com.br/diarios/52810456/dosp-empresarial-06-04-2013-pg-33. Acesso em: 30 nov. 2018. 
apropriação do controle da terra, um processo de financeirização dos recursos do cerrado piauiense.

Sendo assim, entendemos que a ação do mercado imobiliário de terras no Piauí, seja por espólio, arrendamento ou compra mediante capital estrangeiro, além de transformar a terra como um ativo financeiro do mercado internacional, tem contribuído para consolidação do agronegócio como elemento síntese das transformações no espaço rural (SILVA, 2016), passando a interferir na continuidade da pequena produção familiar, na manutenção da cultura e identidade de comunidades locais, na paisagem, no trabalho e no uso da terra e dos recursos naturais.

\section{Considerações Finais}

A convergência de crises instaurada em 2008 e a elevação dos preços do setor alimentício no mesmo ano, ao tempo que intensificaram a corrida por aquisição de terras nos países em desenvolvimento, particularmente no Brasil, denotam a entrada de novas práticas para reprodução do latifúndio.

O interesse político e econômico para expansão da cadeia agroalimentar e do setor de agrocombustíveis, tem repercutido no aumento de áreas para a produção de commodities e na difusão do capital transnacional no sudoeste piauiense, gerando uma crise socioambiental que afeta diariamente as comunidades locais e a preservação do meio ambiente.

Dessa forma, critica-se aqui o discurso do desenvolvimento defendido pelo Estado, pois como ficou exposto, há algo de defeituoso na política adotada. Por isso, diante do quadro de preocupações quanto a sustentabilidade do cerrado piauiense, que inclui a manutenção das comunidades locais, ameaçados pelas rugosidades da expansão do agronegócio, como também devido à complexidade do fenômeno analisado, faz-se necessário levantar algumas questões que não puderam ser respondidas durante os levantamentos bibliográficos e documental, mas que serviram para orientar discussões futuras como: Como as populações do cerrado tem resistido ao avanço do capital imobiliário? Quais estratégias essas populações tradicionais utilizam para marcar seus territórios ante a estrangeirização de terras? Certamente, com o avanço da fronteira agrícola e o fortalecimento ano a ano da Bancada Ruralista no Congresso Nacional, o preço da terra tende a aumentar, acompanhado da estrangeirização, sendo assim, como ficam os movimentos sociais 
do campo nesse cenário, haja vista a ofensiva dos discursos de marginalização desses movimentos por parte dos defensores do capital neoliberal? Qual o futuro ambiental do cerrado piauiense com a intensificação da valorização imobiliária da terra?

Outro ponto a se questionar é a falta de transparência nas informações repassadas sobre o fenômeno da aquisição de terras por atores e grupos estrangeiros, pois ao tempo que dificulta 0 trabalho acadêmico, mostra 0 descomprometimento do Estado para esse assunto e para as consequências sociais e ambientais que eles geram, demonstrando assim a falha ou falta de políticas públicas para redução desse tipo de consequências.

Portanto, o conhecimento das agroestratégias que se reproduzem no sudoeste piauiense e que revelam parte dos modos operantes de como o capital transnacional territorializa os cerrados seguindo o movimento de abertura da fronteira agrícola, mostra-se pertinente para entender as dinâmicas e os dilemas da produção do espaço e orientar a formulação de políticas públicas afirmativas para construção de um projeto de desenvolvimento territorial verdadeiramente sustentável.

\section{REFERÊNCIAS}

ALVES, Vicente Eduardo Lemos. Mobilização e modernização nos cerrados piauiense: formação territorial no império do agronegócio. Tese (Doutorado em Geografia) Faculdade de filosofia, letras e ciências humanas. Universidade de São Paulo, São Paulo, 2006.

BANCO DO NORDESTE, Diário econômico - ETENE. Escritório Técnico de Estudos Econômicos do Nordeste. Ano I. $\mathrm{n}^{\circ}$ 136. 2018. Disponível em: <https://www.bnb.gov.br/documents/1342439/3699577/136_29_08_2018_\%282\%29.pdf/c1c dbf64-3524-7e67-36cd-5b4f2bd9c104>. Acesso em: 02 dez. 2018.

BARROS, Ciro. Fronteira agrícola, retrato de nossos desertos verdes. Agência Pública, 22 mai. 2018. Reportagem. Disponível em: https://outraspalavras.net/outrasmidias/destaqueoutras-midias/matopiba-retrato-de-nossos-desertos-verdes/. Acesso em: 27 nov. 2018.

BORRAS JUNIOR, Saturnino; FRANCO, Jennifer \& WANG, Chunyu. Competing political tendencies in global governance of land grabbing Transnational Institute, Amsterdam, p. 10, 2012.

BRASIL. Lei ํㅜ 5.709, de 07 de outubro de 1971. Regula a Aquisição de Imóvel Rural por Estrangeiro Residente no País ou Pessoa Jurídica Estrangeira Autorizada a Funcionar no Brasil, e dá outras Providências. Brasília, DF, 11 de outubro de 1970, alterada em 2010. 
CASTRO, Luís F. Perdigão de; HERSHAW, Eva ; SAUER, Sérgio . Estrangeirização e internacionalização de terras no Brasil: oportunidades para quem?. Estudos Internacionais. v. 5, p. 74-102, 2018.

CASTRO, Luís Felipe Perdigão de; IGREJA, Rebecca Lemos. Estrangeirização de terras na perspectiva das pormas de colonialidade do agro latino-americano. Revista de Estudos e Pesquisas sobre as Américas, v. 11, n. 2, p. 164-179, 2017.

COMISSÃO PASTORAL DA TERRA. Conflitos no campo - Brasil 2017. Antônio Canuto; Cássia Regina da Silva Luz; Thiago Valentim Pinto Andrade (Cord.). Goiânia. CPT Nacional - Brasil, 208 páginas, 2017.

DATALUTA. Banco de Dados da Luta pela Terra: Relatório Brasil 2017. NERA - Núcleo de Estudos, Pesquisas e Projetos de Reforma Agrária - FCT/ UNESP GIRARDI. E. P. (Cord.). Presidente Prudente, São Paulo, ano 18, Dez. de 2017. Disponível em: https://www.academia.edu/36226328/Relat\%C3\%B3rio_DATALUTA_2017>. Acesso em: 04 dez. 2018.

DEININGER, Klaus. Challenges posed by new wave of framland investment. Journal of Peasant Studies. v.30, n.2, p. 217-247, 2011.

FAIRBAIRN, Madelaine. Foreignition, financialization and land grab regulation. Journal of Agrarian Change, v.15, n.4. 2015.

FAIRHEAD, James; LEACH, Melissa; SCOONES, Ian. Green Grabbing: a new appropriation of nature? The Journal of Peasant Studies, v. 39, n. 2, 237-261, 2012.

FEDERICO, Samuel. Território, capital financeiro e agricultura: Investimentos financeiros estrangeiros no agronegócio brasileiro. São paulo, FAPESP, Relatório Final Pós-Doutorado no laboratoire dynamiques sociales et recomposition des espaces (LADYSS), França, 2016.

HALL, Ruth; SCOONES, Ian; TSIK ATA, Dzodzi. Africa's Land Rush: rural livelihoods and Agrarian Change. NED - New edition.Rochester: James Currey, Boydell \& Brewer, p. 224. 2015.

HERRERA, José Antônio. A estrangeirização de terras na Amazônia Legal brasileira entre os anos 2003 e 2014. CAMPO-TERRITÓRIO: revista de geografia agrária. Edição Especial, p. 136-164, jun. 2016.

INSOLO AGROINDUSTRIAL. Disponível em: <http://www.insolo.com.br/historia.html> Acesso em: 21 jan. 2019.

LAND MATRIX. Web of transnational delas. 2018. Disponível em:

https://landmatrix.org/en/get-the-idea/web-transnational-deals/. Acesso em: 29 jan. 2019.

LEITE, Alexandre Cesar Cunha; LIMA, Thiago. Aquisição Transnacional de Terras (Land Grabbing). Estudos Internacionais. Belo Horizonte. v.5. n.2. 2017.

LEITE, Ana Carolina Gonçalves. O campesinato no Vale do Jequitinhonha: da sua formação no processo de imposição do trabalho à crise da (sua) reprodução capitalista. Tese. (Doutorado em Geografia Humana) - Faculdade de filosofia, letras e ciências humanas. Universidade de São Paulo, São Paulo, 2015.

LUCON, Oswaldo; GOLDEMBERG, José. Crise financeira, energia e sustentabilidade no Brasil. Estudos Avançados, 23 (65), 2009. 
MARQUES, Rosa Maria; NAKATANI, Paulo. Crise, Capital fictício e afluxo de capitais estrangeiros no Brasil. Caderno CRH. Salvador, v.2, n.67, p.65-78. 2013.

MIRANDA, Rego Rogério; SILVA, Marcos Alexandre Pimentel da. Das agroestratégias aos eixos territoriais do agronegócio no estado do Pará. Boletim DATALUTA n. 99. Artigo do mês, mar. 2016.

MORAES, Maria Dione de Carvalho. Um povo do cerrado entre baixões e chapadas: modo de vida e crise ecológica de camponeses(as) nos cerrados do sudoeste piauiense. In:

GODOI, E. P. de; MENEZES, M. A. de; MARIN, R. A. (Orgs.). Diversidade do

campesinato: expressões e categorias. v. 2 (estratégias de reprodução social). São Paulo: Unesp; Brasília: Núcleo de Estudos Agrários e Desenvolvimento Rural, 2009. pp. 131-161.

OLIVEIRA, Gustavo de L. T. Regularização fundiária e a "corrida mundial por terras" no Brasil. Campo - Território: Revista de geografia agrária. Edição especial. 43-75, jun. 2016.

PELUSO, Nancy Lee; LUND, Christian. New frontiers of land control: Introduction. Journal of Peasant Studies. 38:4, 667-681. 2011.

PEREIRA, Lorena Izá; PAULI, Lucas. O processo de Estrangeirização da Terra e expansão do agronegócio na região do MATOPIBA. Campo - Território: Revista de geografia agrária. Edição especial, p.196-224, jun., 2016.

REDE SOCIAL DE JUSTIÇA E DIREITOS HUMANOS, GRAIN, INTER PARES, AND SOLIDARITY SWEDEN - LATIN AMERICA. Foreign pension funds and land grabbing in Brazil, p. 1-16, nov. 2015.

REDE SOCIAL DE JUSTIÇA E DIREITOS HUMANOS. Imobiliárias agrícolas transnacionais e a especulação com terras na região do MATOPIBA. Outras expressões. 2018.

RIDELL, Phil. 'Land Grabs' and alternative modalities for agricultural investments in emerging markets. In. ALAN, Tony; KEULERTZ, Martin; SOJAMO, Suvi; WARNER, Jeroen. Handbook of Land and Water Grabs in Africa. London, Routledge, 2013. p. 160 - 178.

RUFO, Tiago Fernandes. Modernização agrícola no Sudoeste Piauiense: Impactos na rede urbana regional, no meio ambiente e nas comunidades. Monografia (Monografia em Geografia). Universidade Nacional de Brasília, Brasília - Distrito Federal, dez. 2013.

SASSEN, Saskia. Expulsões - Brutalidade e Complexidade na Economia Global. Paz \&Terra. 2016.

SAUER, Sérgio; LEITE, Sérgio Pereira. Expansão agrícola, preços e apropriação de terra por estrangeiros no Brasil. Revista de Economia e Sociologia Rural. v. 50, n. 3, p. 503524, jul/set. 2012.

SILVA, Antonio Joaquim da. Agricultura familiar e a

territorialização/desterritorialização/reterritorialização provocada pelo agronegócio no cerrado piauiense: Hibridismo sociocultural marginal em Uruçuí. 2016. Tese (Doutorado em Desenvolvimento e Meio Ambiente) - Universidade Federal do Piauí, Teresina, 2016.

VINHA, Janaina Francisca de Souza Campos; PEREIRA, Lorena Izá. ESTRANGEIRIZAÇÃO DE TERRAS E A GEOPOLITIICA DA QUESTÃO AGRÁRIA: a usina UMOE Bioenergy in Sandovalina - SP. Campo - Território: Revista de geografia agrária. Edição especial, p. 257-284, jun., 2016. 


\section{NOTAS DE AUTOR}

\section{CONTRIBUIÇÃO DE AUTORIA}

Elayne de Silva Figueredo - Investigação, concepção, elaboração do manuscrito, revisão e aprovação da versão final

Giovana Mira de Espindola - Concepção, elaboração do manuscrito, revisão e aprovação da versão final do trabalho.

Antonio Joaquim da Silva - Participação ativa da discussão dos resultados, revisão e aprovação da versão final do trabalho.

Márcia Leila de Castro Pereira - Elaboração do manuscrito, revisão e aprovação da versão final do trabalho.

\section{FINANCIAMENTO}

Conselho Nacional de Desenvolvimento Científico e Tecnológico - CNPq, pela bolsa de mestrado concedida ao primeiro autor.

\section{CONSENTIMENTO DE USO DE IMAGEM}

Não se aplica

\section{APROVAÇÃO DE COMITÊ DE ÉTICA EM PESQUISA}

Não se aplica

\section{CONFLITOS DE INTERESSE}

Não se aplica

\section{LICENÇA DE USO}

Este artigo está licenciado sob a Licença Creative Commons CC-BY. Com essa licença você pode compartilhar, adaptar, criar para qualquer fim, desde que atribua a autoria da obra.

\section{HISTÓRICO}

Recebido em: 31-01-2019

Aprovado em: 14-02-2019 